\title{
Congenital absence of the intrahepatic segment of the inferior vena cava with azygos continuation presenting as a mediastinal
} mass

\author{
R.J. Beedie, W. Yeo ${ }^{1}$ and S.K. Morcos
}

Departments of Diagnostic Radiology and ${ }^{1}$ Infectious Diseases, Lodge Moor Hospital, Sheffield, S10 4LH, UK.

\begin{abstract}
Summary: A child with the isolated anomaly of azygos continuation of the inferior vena cava is presented. The interest of this abnormality lies in its detection as a mediastinal mass on the chest radiograph. Computed tomography with intravenous contrast enhancement is the method of choice to diagnose this venous anomaly. Awareness of the caval-azygos abnormality is important to surgeons and cardiologists. Accidental ligation of the azygos vein is fatal and cardiac catheterization using the lower extremity vein is troublesome in patients with this condition.
\end{abstract}

\section{Introduction}

Congenital absence of the hepatic segment of the inferior vena cava is a well recognized but uncommon anatomic variant. Venous drainage from below the diaphragm is carried by the azygos system to the superior vena cava. The hepatic veins drain directly into the right atrium. ${ }^{1,2} \mathrm{~A}$ case of this anatomic variant in a child is presented. The radiological features and the importance of this condition are discussed.

\section{Case report}

A previously well six year old boy was admitted with an upper respiratory tract infection. Chest radiograph on admission demonstrated clear lungs, widening of the superior mediastinum to the right and slight displacement at the lower part of the para vertebral edge of the right lung.

The child made an uneventful recovery; however, the appearance of the superior mediastinum remained abnormal on the follow-up chest radiograph (Figure 1). The lateral view was unhelpful. The differential diagnosis which was considered included large lymph nodes, mediastinal mass or cyst and vascular anomalies such as double aortic arch.

A barium swallow was performed and revealed no abnormal oesophageal indentations. Computed tomography (CT) of the thorax, with intravenous contrast enhancement showed a dilated azygos vein

Correspondence: S.K. Morcos, F.R.C.S., F.R.C.S.I., F.R.C.R.

Accepted: 19 October 1988 which could be followed up to the azygos arch where it joined a distended superior vena cava (Figure 2a, b). Ultrasound scanning of the abdomen demonstrated the absence of the intrahepatic portion of the inferior vena cava and the hepatic veins draining into the right atrium via a single channel (Figure $3 a, b)$. A distended azygos vein lying to the right of the upper abdominal aorta was also noted. No evidence of other congenital anomalies was found. Echocardiograph examination demonstrated a normal heart.

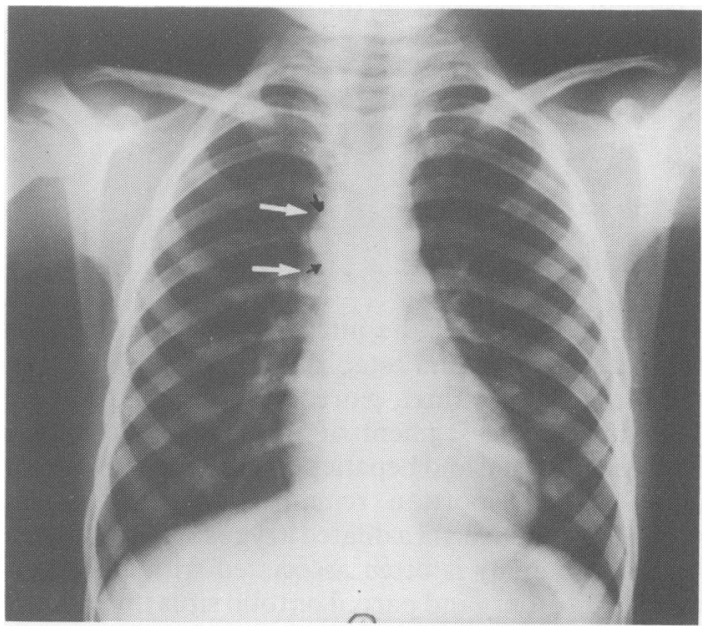

Figure 1 A follow up postero-anterior chest radiograph reveals an abnormal superior mediastinum. The dilated azygos arch (black arrows) is seen end on. The edge of the distended superior vena cava is outlined by white arrows.

(C) The Fellowship of Postgraduate Medicine, 1989 

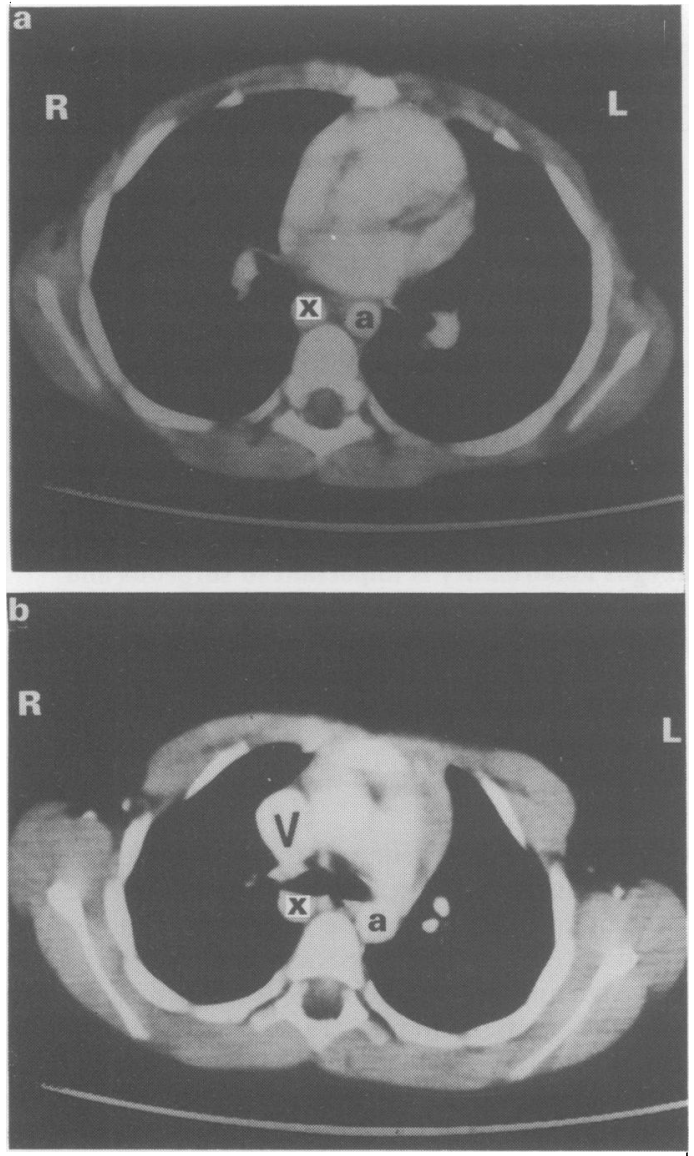

Figure $2(a, b) C T$ scans of the thorax with intravenous contrast enhancement in (b) demonstrate the dilated azygos vein ( $x$ ) adjacent to the descending thoracic aorta (a). The superior vena cava (V) is distended.

\section{Discussion}

The development of the inferior vena cava involves fusion, regression and establishment of midline anastomoses between three paired fetal venous systems. The supra renal segment of the inferior vena cava between the renal and hepatic veins may fail to develop and its lower portion remains connected to the superior vena cava via a dilated azygos system ${ }^{2}$ (Figure 4). This anomaly is often associated with congenital cardiac disorders and partial or total situs inversus. ${ }^{1,3,4}$ The supra renal interruption of the inferior vena cava with azygos continuation per se is harmless and may rarely exist as an isolated anomaly as in this case.

The interest of this condition lies in its presentation
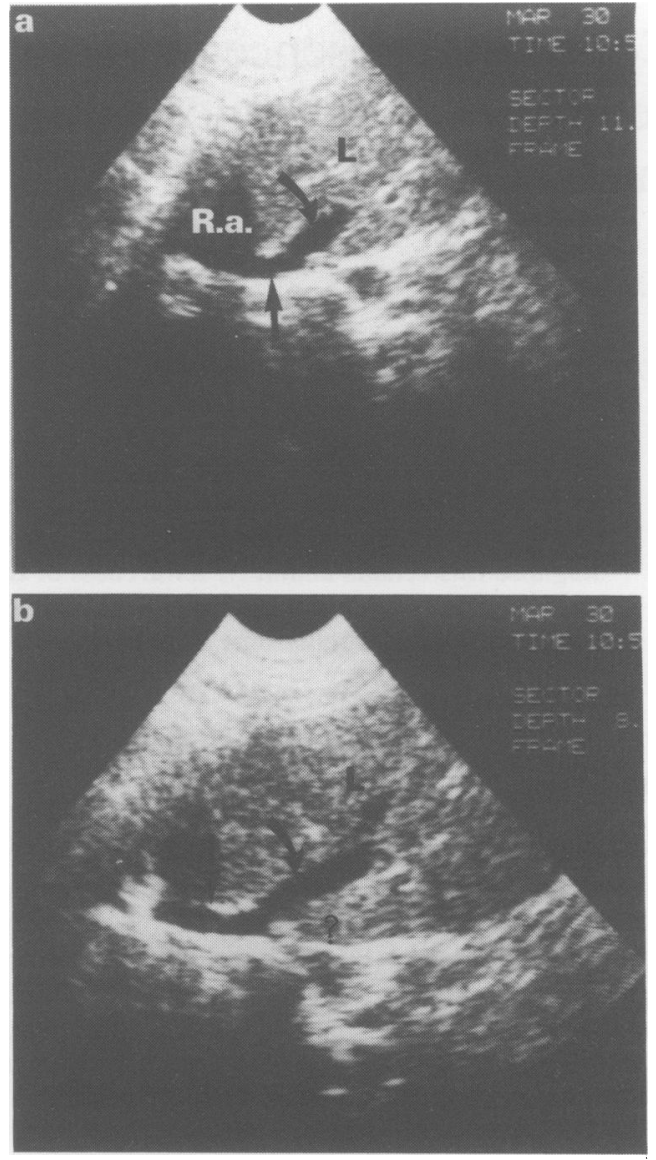

Figure 3 (a,b) Sagittal ultrasound scans of the right lobe of the liver (L) near the mid line demonstrate a hepatic vein (curved arrow) draining into the right atrium (R.a) via a single channel (straight arrow) and the absence of the intra hepatic portion of the inferior vena cava (?).

as a mediastinal abnormality on the chest radiograph The plain film findings include widening of the superior mediastinum to the right, large azygos arch and displacement of lower part of the para vertebral edge of the right lung, ${ }^{4}$ Intravenous contrast enhanced CT scan of the thorax and abdomen is the most reliable single technique for diagnosing this condition and differentiating it from pathological mediastinal lesions and other vascular anomalies. ${ }^{3,5}$ Ultrasound scanning can be helpful in demonstrating the intraabdominal part of the dilated azygos vein and the absence of the intrahepatic segment of the inferior vena cava. Associated congenital abnormalities can also be investigated by these modalities.

Finally, knowledge of this condition is important to 


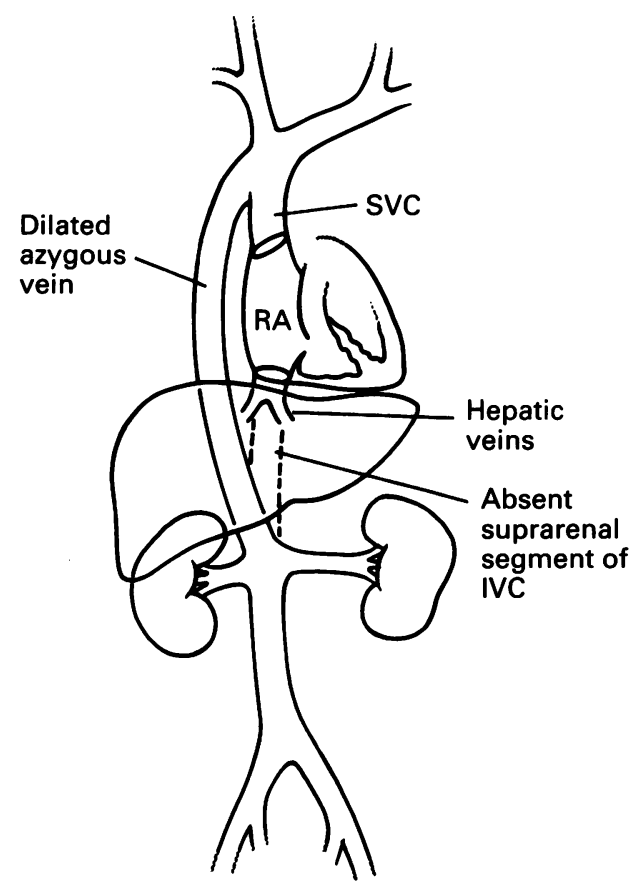

\section{References}

1. Chuang, V.P., Mera, C.E. \& Hoskins, P.A. Congenital anomalies of the inferior vena cava. Review of embryogenesis and presentation of a simplified classification. Br J Radiol, 1974, 47: 206-213.

2. Mayo, J., Gray, R., St Louis, E., Grosman, H., McLoughlin, M. \& Wise, D. Anomalies of the inferior vena cava. Am J Roentgenol, 1983, 140: 339-345.

3. Webb, W.R., Gamsu, G., Speckman, J.M., Kaiser, J.A., Federle, M.P. \& Lipton, M.J. Computed tomographic demonstration of mediastinal venous anomalies. Am J Roentgenol, 1982, 139: 157-161.
Figure 4 Diagram demonstrating the congenital anomaly of absence of the suprarenal segment of the inferior vena cava (IVC) with azygos vein continuation which drains into the superior vena cava (SVC). [Right atrium (RA)].

the surgeon since ligation of the azygos vein, the only major route of venous drainage from below the diaphragm may result in death. ${ }^{6}$ The caval-azygos anomaly is also troublesome to cardiologists attempting cardiac catheterization if a lower extremity vein is used. $^{4}$

\section{Acknowledgement}

We are grateful to Dr M. McKendrick, Consultant Physician at Lodge Moor Hospital for his permission to report this case.

4. Berdon, W.E. Plain film findings in azygos continuation of the inferior vena cava. Am $J$ Roentgenol, 1968, 104: 452-457.

5. Smathers, R.L., Buschi, A.J., Pope, T.L., Brenbridge, A.N. \& Williamson, B.R. The azygos arch. Normal and pathologic CT appearance. Am J Roentgenol, 1982, 139: 477-483.

6. Effler, D.B., Greer, A.E. \& Sitters, E.C. Anomaly of the vena cava inferior. Report of fatality after ligation. JAMA, 1951, 146: $1321-1322$. 